Corrigendum

\title{
Corrigendum to "Percutaneous Transforaminal Endoscopic Lumbar Interbody Fusion: Clinical and Radiological Results of Mean 46-Month Follow-Up"
}

\author{
Sang-Ho Lee, ${ }^{1}$ H. Yener Erken, ${ }^{2}$ and Junseok Bae ${ }^{1}$ \\ ${ }^{1}$ Department of Neurological Surgery, Spine Health Wooridul Hospital, Seoul, Republic of Korea \\ ${ }^{2}$ Department of Orthopaedic Surgery, Spine Health Wooridul Hospital, Seoul, Republic of Korea \\ Correspondence should be addressed to Junseok Bae; jsbaemd@gmail.com
}

Received 10 April 2017; Accepted 24 April 2017; Published 12 July 2017

Copyright (c) 2017 Sang-Ho Lee et al. This is an open access article distributed under the Creative Commons Attribution License, which permits unrestricted use, distribution, and reproduction in any medium, provided the original work is properly cited.

In the article titled "Percutaneous Transforaminal Endoscopic Lumbar Interbody Fusion: Clinical and Radiological Results of Mean 46-Month Follow-Up" [1], the images of
Figures 1 and 2 are reversed. They should be corrected as follows.

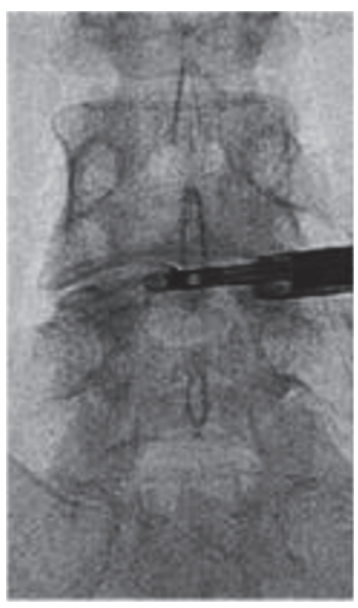

(a)

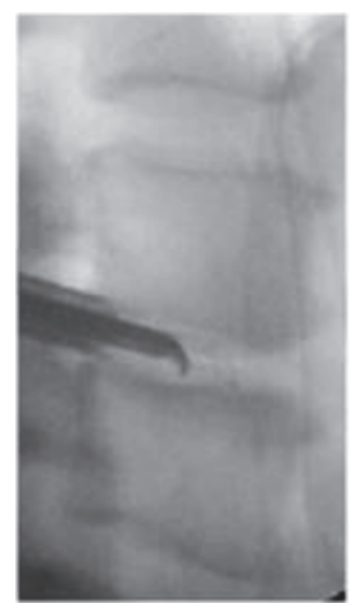

(b)

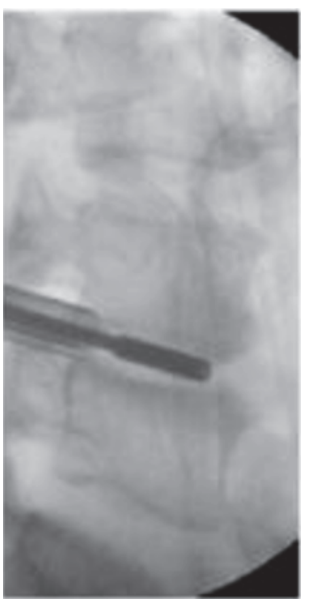

(c)

Figure 1: Continued. 


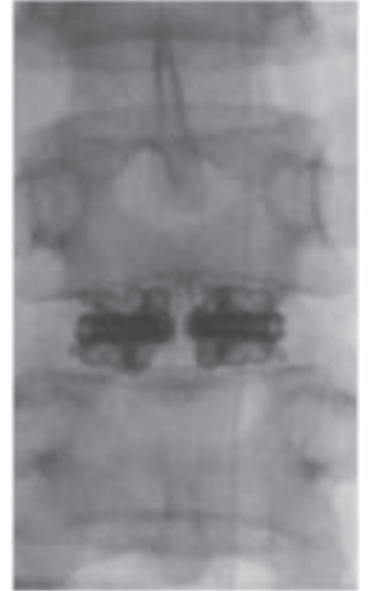

(d)

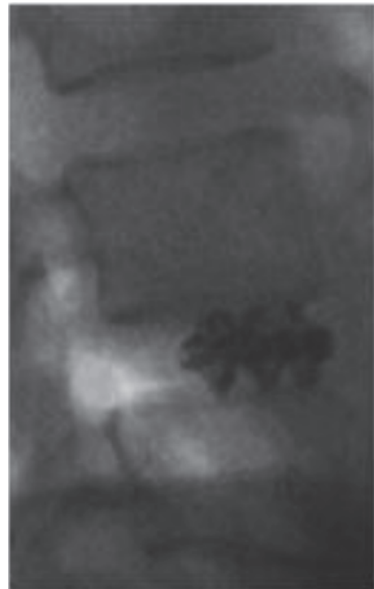

(e)

FIGURE 1: Representative case involving a patient with DDD and instability at the L4-5 level. (a-b) Fluoroscopic images showing disc removal using endoscopic forceps and endplate preparation using an endoscopic curette. (c) A trial implant without expansion in disc space is shown. (d-e) Fluoroscopic images showing the final construct with an expandable B-Twin spacer.

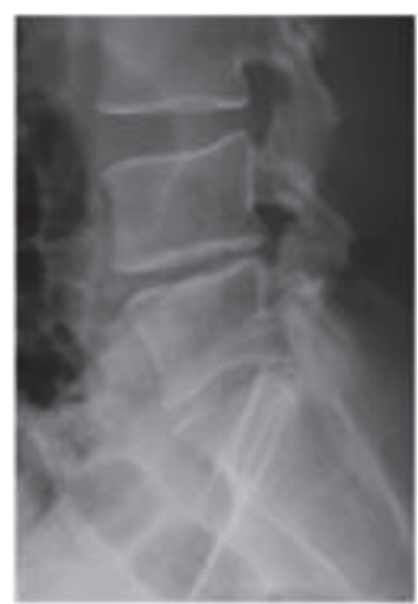

(a)

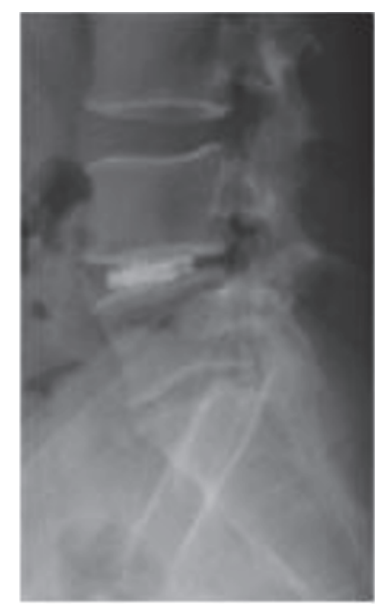

(b)

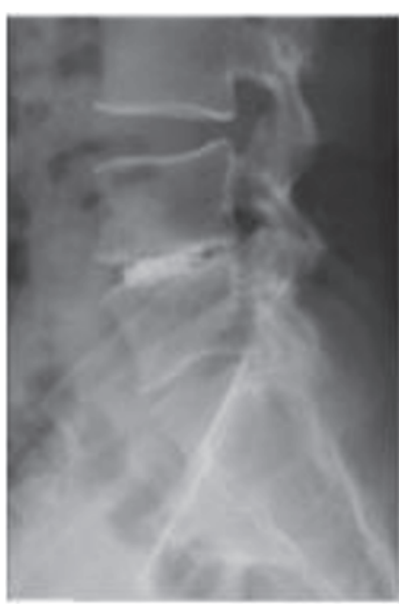

(c)

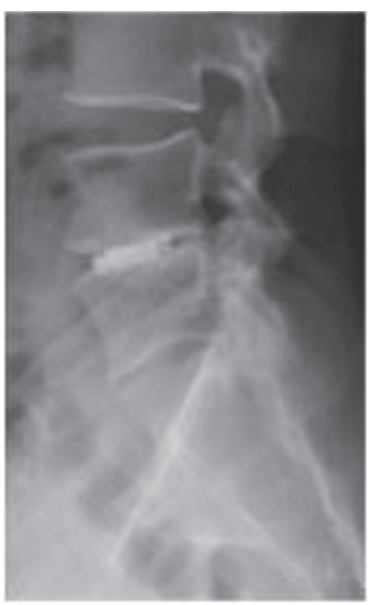

(d)

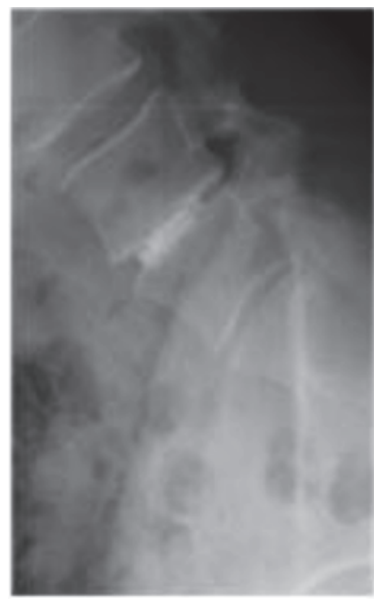

(e)

Figure 2: A 37-year-old male patient (patient number: 15 in the tables) with DDD and HNP at the L4-5 level. Lateral standing X-rays showing (a) preoperative, (b) early postoperative, and (c, d, e) final follow-up X-rays including standing lateral neutral, extension, and flexion views taken at 50 months after the surgery. Note that there is $1.9 \mathrm{~mm}$ reduction of the $\mathrm{DH}$ at the final follow-up examination compared to the early postoperative period. The operated level remained stable in extension and flexion views. The patient's VAS-B, VAS-L, and ODI scores were $1.4,2,4.4$, respectively, at the final follow-up visit. The patient rated his result as "excellent." 


\section{References}

[1] S.-H. Lee, H. Yener Erken, and J. Bae, "Percutaneous transforaminal endoscopic lumbar interbody fusion: clinical and radiological results of mean 46-month follow-up," vol. 2017, Article ID 3731983, 9 pages, 2017. 


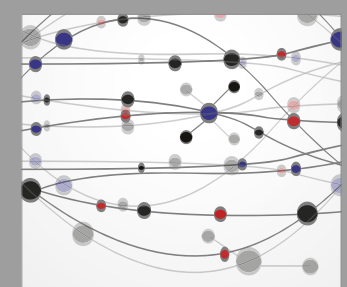

The Scientific World Journal
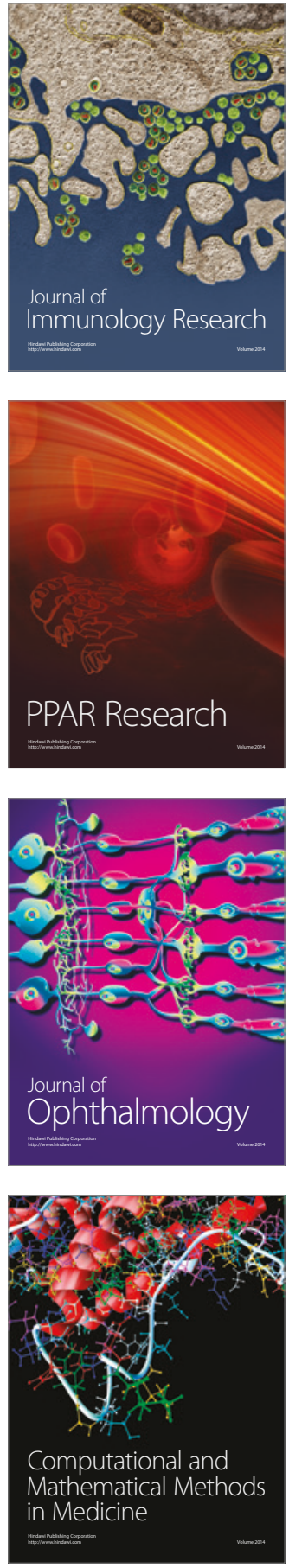

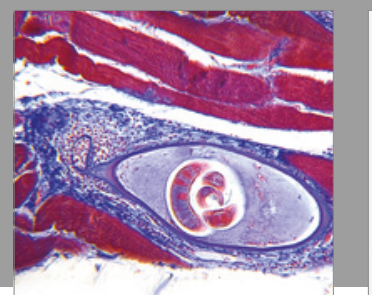

Gastroenterology Research and Practice
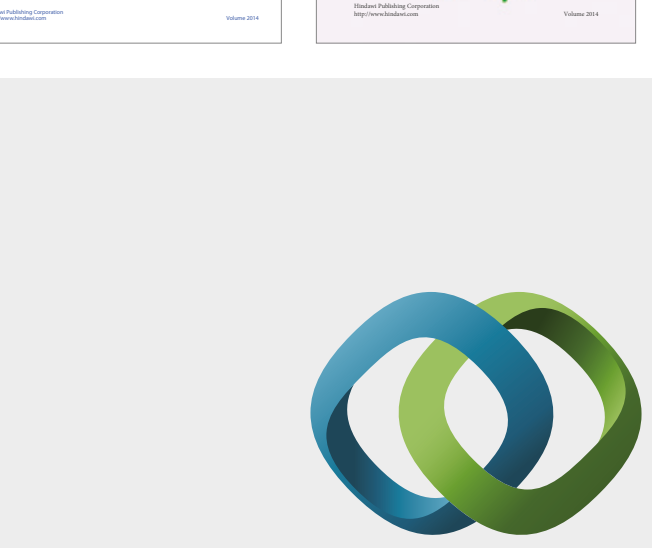

\section{Hindawi}

Submit your manuscripts at

https://www.hindawi.com
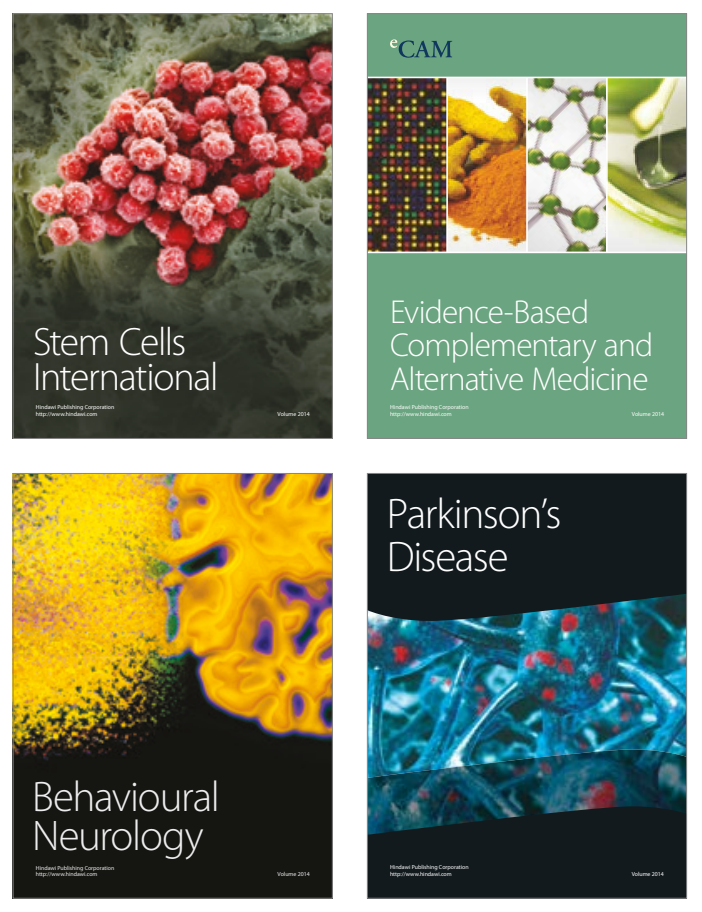
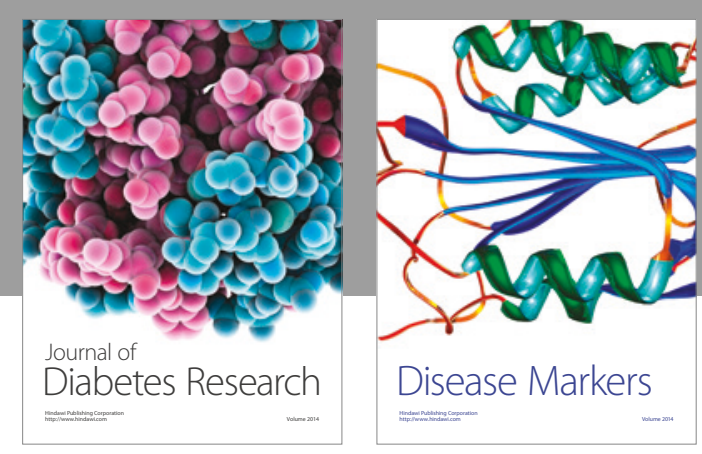

Disease Markers
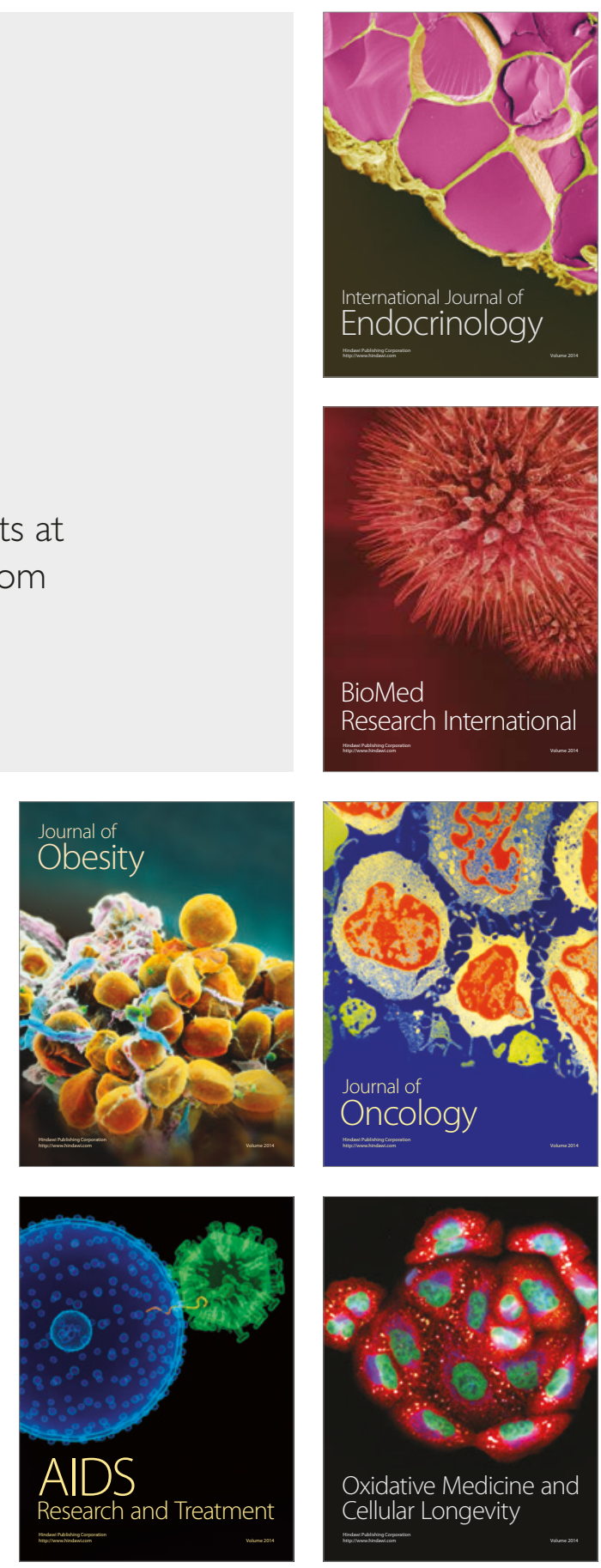